\title{
Hippocampal unit response during temporal single alternation of classical conditioning with rewarding brain stimulation in the rat
}

\author{
TOSHITSUGU HIRANO and MASAHIRO YAMAGUCHI \\ Kyoto University, Kyoto, Japan
}

\begin{abstract}
To evaluate hippocampal function on working memory, an experiment of rewarding classical conditioning with a temporal single-alternation (SA) paradigm was conducted. White rats that showed positive self-stimulation to the lateral hypothalamus were trained on an SA schedule with 60-sec intervals, in which reinforced trials (R; CS-US) were regularly alternated with nonreinforced trials ( $\mathrm{N}$; CS alone). Unit activity from the hippocampus and the animals' movements were recorded during the pairing of auditory CS and lateral hypothalamic stimulation (US). When the experimental schedule was shifted to SA from pseudoconditioning, the hippocampal unit activity increased in the CS periods on both $\mathrm{R}$ and $\mathrm{N}$ trials in the absence of behavioral response alternation. During SA training, hippocampal unit activity in the CS period significantly increased on $\mathrm{R}$ trials relative to $\mathrm{N}$ trials, when a differential behavioral response also appeared. No detectable differences in the hippocampal unit background pre-CS levels were found between $R$ and $\mathrm{N}$ trials. The results are discussed in terms of the interaction between working memory and reference memory in the hippocampal function.
\end{abstract}

In a recent study using classical conditioning of the rabbit nictitating membrane (NM) response, Hoehler and Thompson (1979) found that a temporal single-alternation (SA) schedule produced differential responses in hippocampal units on reinforced $(\mathrm{R})$ and nonreinforced $(\mathrm{N})$ trials with no evidence of behavioral discrimination. In those experiments, rabbits were trained with an SA schedule in which $\mathrm{R}$ trials (CS-US) were regularly alternated with $\mathrm{N}$ trials (CS alone). They showed clear discrimination of the differential significance of $\mathrm{R}$ - and $\mathrm{N}$-trial stimulus aftereffects in hippocampal unit activity, in which two consequences were recognized: (1) pre-CS background unit activity levels that were lower on $\mathrm{R}$ trials than on $\mathrm{N}$ trials, and (2) levels of unit activity in the CS periods that were higher on $\mathrm{R}$ trials than on $\mathrm{N}$ trials. These results were interpreted to support the notion of an important role for the hippocampus in "working memory," as proposed by Honig (1978). That is, working memnry contains information relevant to a single trial, whereas reference memory contains information relevant to all trials.

The two dominant views of hippocampal function at present are the "working memory" hypothesis (Olton, Becker, \& Handelmann, 1979) and the "cognitive map"' hypothesis (O'Keefe \& Nadel, 1978). Unit recording

This work was supported by grants in aid for scientific research to T. Hirano from the Ministry of Education, Japan. A part of the results of this study was presented in the poster session of the Symposium on Conditioning, November 1983, at Woods Hole, MA. The authors are especially grateful to John F. Disterhoft, Northwestern University, for his critiques of an earlier draft. Requests for reprints should be sent to Toshitsugu Hirano, Department of Psychology, Faculty of Letters, Kyoto University, Kyoto, Japan 606. studies (O'Keefe \& Conway, 1980; O'Keefe \& Dostrovsky, 1971; Olton, Branch, \& Best, 1978) as well as even more lesion studies (see Black, Nadel, \& O'Keefe, 1977; Nadel, 1980; Nadel \& Willner, 1980) support the "cognitive map" hypothesis. There is no unit recording data to support the working memory hypothesis directly except for the research mentioned above. As shown by Olton, Becker, and Handelmann $(1979,1980)$, the usual behavioral deficit produced by hippocampal lesionentering the same path already visited in a radial maze task-might be interpreted as a lack of working memory as well as the lack of a cognitive map. In order to identify which hypothesis might be valid, it would seem important to examine hippocampal unit activity in paradigms in which no spatial cues are present.

The temporal SA paradigm is a task that involves no spatial cues (Hoehler \& Thompson, 1979). It requires the animal to process internal cues based on aftereffects of a prior stimulus, whether it was an $\mathrm{R}$ or an $\mathrm{N}$ trial. In order to examine the generality of Hoehler and Thompson's findings in the nictitating membrane conditioning, a type of defensive conditioning, the present experiment was undertaken to study hippocampal function in a rewarding type of conditioning. In addition, rats were used as subjects, because this species exhibits a more welldeveloped patterning behavior in appetitive conditioning than the rabbit trained with NM conditioning (Capaldi, 1967). Thus, if the hippocampal function is related to the memory process, we might expect to see differential unit activity developing in the hippocampus over the course of the SA paradigm.

In a previous study (Hirano, 1984), we found that conditioning of an auditory stimulus with rewarding brain 
stimulation could be used as a paradigm for studying unit changes in several areas, such as the septo-hippocampal system. We applied this conditioning procedure to the temporal SA paradigm in the present experiment. Since it was also of interest to detect any changes in unit activity after the change from random presentation of CS and US (pseudoconditioning) to the SA paradigm in which $\mathrm{R}$ trials were regularly alternated with $\mathrm{N}$ trials, pseudoconditioning was given in the first session and followed thereafter by the SA session.

\section{METHOD}

Data from 19 albino male rats, 6-9 months of age and weighing $310-415 \mathrm{~g}$, are reported here. General methods of surgery, conditioning, data analysis, and histology were similar to those reported previously (Hirano, 1984; Sakurai \& Hirano, 1983). Briefly, each rat was prepared with eight recording electrodes (nichrome wires of 62.5- $\mu \mathrm{m}$ diameter), bipolar stimulation electrodes (stainless steel wire of $200-\mu \mathrm{m}$ diameter), and a reference lead under nembutal anesthesia (40 mg/kg body weight). Stereotaxic coordinates for implantation of chronic electrodes in the septum, dentate, and dorsal hippocampus for recording and the lateral hypothalamus for stimulation were derived from the König and Klippel (1963) atlas of the rat brain. Bipolar stimulation electrodes were implanted in the anterior and middle parts of the lateral hypothalamus. The electrodes were then cemented to a permanently implanted 9-conductor Amphenol miniature plaque for recording microelectrodes and another 4-conductor miniature plaque for the stimulation electrodes.

\section{Self-Stimulation Test}

Following 7 days of recovery, all subjects were trained to press a lever for lateral hypothalamic stimulation in 1-h daily sessions for 3 consecutive days. The stimulation was a 0.5 -sec train of biphasic rectangular pulses of $60-\mathrm{Hz}$ alternating current of $0.5-\mathrm{msec}$ duration. During these sessions, the hypothalamic placement that produced the greater positive rewarding effect was determined and then used throughout the rest of the experiment. On the 3rd day of this self-stimulation test, current strength for each subject was set to produce a $300-500$ response rate during a 15 -min interval (100 to $200 \mu \mathrm{A})$.

\section{Unit Recording}

Three daily sessions of classical conditioning were given, starting from the day following the last self-stimulation session. The animals were introduced to the circular training apparatus, the same one used in the self-stimulation test, with the lever withdrawn. The animals were relatively free to move, with no restraint in the apparatus during the course of the experiment. A loudspeaker, mounted $40 \mathrm{~cm}$ above the animal, provided a pure tone of $2 \mathrm{kHz}$ for $1 \mathrm{sec}$. A video camera was set to record the behavior of the animal for every trial during the session.

Unit recording was made simultaneously from four probes during 2-sec intervals, which included a 1-sec prestimulus interval and a 1-sec interval of auditory stimulation. The rat's plaque was connected to a 9-contact plug, which led through a low-noise Microdot cable and a slip-ring commutator to a panel into which field effect transistor preamplifiers were directly plugged. Stimulation electrodes were connected through the commutator as well. The weights of the plug, cord, commutators, and preamplifiers were counterbalanced so that the animal could move freely inside the apparatus. Attached to the cable was a noisy "hearing aid" open-ended wire, which served as a movement detector by amplifying the voltage generated by the animal's movements. The $500-10000-\mathrm{Hz}$ frequency-range signals from the preamplifier were fed into an am- plifier located outside the apparatus (see also Olds, 1973; Olds \& Hirano, 1969). The output of the amplifier was fed into a unit window discriminator, which used the amplitude and the fall time of a spike as criteria for signal selection. It could reject spikes of different amplitudes or durations, as well as various noises. The discriminator, on detection of a spike, produced a $0.5-\mathrm{msec}$ pulse, which was recorded on a cassette recorder.

\section{Classical Conditioning}

Classical conditioning was conducted on 3 successive days. Each day was divided into two equal sessions. During the first session on the 1st day, pseudoconditioning was given, in which delivery of the CS (auditory stimulus, $2 \mathrm{kHz}: 1 \mathrm{sec}$ ) and US (the lateral hypothalamic stimulation, 4 trains of 0.5 -sec stimulation at $0.5-\mathrm{sec}$ intervals) were random, with an average interstimulus interval of $40 \mathrm{sec}$. The CS was presented 300 times and the US 150 times in a 6-h period. During the second training session on Day 1, pseudoconditioning was followed by conditioning of rewarding brain stimulation. A schedule of alternating reinforced (R; CS-US) and nonreinforced (N; CS-alone) trials, with CS-US onset intervals of $500 \mathrm{msec}$ and intertrial intervals of $60 \mathrm{sec}$, was used. As in the pseudoconditioning session, to ensure the rewarding effect, the US consisted of four trains of hypothalamic stimulation given to the subject at 0.5 -sec intervals. Thus, during the SA schedule, the same frequencies of occurrence for CS and US were applied as in the preceding pseudoconditioning session. During this conditioning session with the temporal SA paradigm, the animals received $150 \mathrm{R}$ and $150 \mathrm{~N}$ trials in $6 \mathrm{~h}$, with $\mathrm{R}$ trials regularly alternated with $\mathrm{N}$ trials. Thus, paired CS-US trials were invariably preceded by CSalone trials and CS-alone trials were invariably preceded by the paired CS-US trials.

On Days 2 and 3, the animals were trained with conditioning on the SA paradigm throughout the first and second sessions, each of which included $150 \mathrm{R}$ and $150 \mathrm{~N}$ trials. The experiment was run at night, starting at 7:00 p.m. and ending at 7:00 a.m. on the following day. The animals were returned to their home cages and fed during the daytime before the next training session was started. Water was ad lib during the experiment. The experiment was controlled by a microcomputer.

\section{Histology}

At the end of the experiment, the animals were sacrificed by means of terminal anesthesia. Lesions for identification of recording points were formed by passing positive $20-\mu \mathrm{A}$ current for $30 \mathrm{sec}$ through the tips of each electrode. The animals were perfused through the heart with .9 saline followed by $10 \%$ Formalin. The brain was then sliced into 50- $\mu \mathrm{m}$ frozen sections and stained with cresyl violet to determine electrode location. For histological examination, verification of the electrode placement was made with an enlarged photoprojector.

\section{Data Collection and Analysis}

After the experiment was completed, the digital output of the various discriminators was collected by the microcomputer. Unit activity was sampled during $480 \mathrm{msec}$ prior to the application of stimuli and for $480 \mathrm{msec}$ from the onset of the tones. The data were gathered in successive 8-msec bins. To evaluate (1) the difference in firing rate after conditioning with the SA paradigm and (2) the difference in firing rate between $\mathrm{R}$ and $\mathrm{N}$ trials during the SA schedule, a standardized firing histogram for each unit was prepared from the last 100 trials of every session. For this purpose, the number of firings in three successive bins (24-msec interval) were grouped and stored for further analysis. The behavioral movement data were analyzed in the same way.

Two types of analysis were performed. First, an averaged firing histogram was prepared for every unit for every session, each covering 100 trials (excluding the first 50 trials of a session). The mean and standard deviation of the firing rate for the 20 background in- 
tervals was calculated. The averaged firing rate in 20 successive intervals (each $24 \mathrm{msec}$ ) during the CS-US period was then converted to standard scores by subtracting their mean firing rate from the mean of the background and dividing by the standard deviation of the background (Olds, Disterhoft, Segal, Kornblith, \& Hirsh, 1972). The firing histogram was plotted in terms of Z-scores for 20 successive intervals $(480 \mathrm{msec})$ for each unit response as well as for the 20 intervals $(480 \mathrm{msec})$ in the pre-CS period. This analysis was performed for each unit for every session over 3 days of the experiment. Second, summary analysis of the data was done. The $480-\mathrm{msec}$ period before and after the CS presentation was divided into four quarters of $120 \mathrm{msec}$ each (Q-score), comprising five successive intervals of $24 \mathrm{msec}$. For each of those intervals, averaged standard scores were calculated by grouping five intervals as described for the $24-$ msec periods.

Since Day 1 comprised pseudoconditioning in the first session followed by conditioning of an SA paradigm in the second session, any change of unit activity would be considered to be due to the procedural shift, that is, to the effect of a change in the stimulusreinforcement contingency. In order to evaluate the differences between $\mathrm{R}$ and $\mathrm{N}$ trials in the SA schedule across Days 1 to 3, the data of the second session on each day were compared. These were relatively stable states that occurred in the same periods of the night, and thus a difference between them would be the consequence of conditioning with the SA paradigm.

Furthermore, as noted by Capaldi (1967), Hoehler and Leonard (1973), and Hoehler and Thompson (1979) in their discussions concerning the patterning behavior produced by the SA paradigm with a fixed intertrial interval, such as in the present experiment, $\mathrm{N}$ trials occur $60 \mathrm{sec}$ after the last rewarding brain stimulation, whereas $\mathrm{R}$ trials occur $120 \mathrm{sec}$ after the last stimulation. Therefore, in order to examine whether there were different levels of pre-CS unit activity between $\mathrm{R}$ and $\mathrm{N}$ trials which might exhibit differential aftereffects of the previous trial, the frequency of each unit firing was examined from the last 100 trials of the second session on Day 3. For this analysis, relative frequency of unit firing during 8-msec bins was evaluated for both unit and movement data during the pre-CS periods sampled separately from the $R$ and $N$ trials.

\section{RESULTS}

A total of 65 units from 19 animals were identified, recorded, and passed the various quality criteria. These units were divided into three main groups by areas: the dentate gyrus (18 units), CA1-3 (27 units), and septum (20 units). The stimulating electrodes were found in the anterior or middle part of the lateral hypothalamus (Figure 1). Due to the occasional disappearance of unit activity over time, the data of several electrodes were discarded. This caused a decreasing number of units on successive days. The movement data of two animals on Days 1 and 2 and of four animals on Day 3 were discarded because amplifier noise was found in the data analysis.

An example of the summarized data is presented in Figure 2, which depicts the animal's movement (upper portion) and unit responses (lower three portions) during pseudoconditioning on the 1st day (the leftmost portion) and following the SA paradigm on Days 1-3 in terms of standard scores averaged over all animals separately for $\mathrm{R}$ and $\mathrm{N}$ trials during the SA sessions. Each point in the figure represents averaged responses in terms of the $\mathrm{Q}$ score combined for $120-\mathrm{msec}$ intervals, thus shaping a standardized poststimulus histogram during CS presentation.

\section{Behavior}

As shown in Figure 2, there was moderate behavioral inhibition to the tone during the pseudoconditioning session. However, the animals developed differential conditioned movement to the tone by the 3rd day of SA training: they developed conditioned movement to the tone for $\mathrm{R}$ trials, but remained at almost the same inhibition level for $\mathrm{N}$ trials. Inspection of the video tape recording showed that the observed movements after conditioning varied among animals: the main responses observed were generally head turning or forward movement combined with some manifestations such as nose twitch, sniffing, jaw movement, chewing, or bodily shaking. All these responses could be sensitively detected by the headmovement detector.

First, a two-way analysis of variance was performed on the movement data in order to detect differences between treatments ( $\mathrm{R}$ vs. $\mathrm{N}$ trials) and between successive 120 -msec intervals (periods). The results of the analysis are presented below the graph for each group and each session in Figure 2. The significant differences between movements in the $\mathrm{R}$ and $\mathrm{N}$ trials did not appear until Day 2 $[F(1,128)=12.20, p<.01]$; these differences increased on Day $3[F(1,112)=27.64, p<.01]$, when the training was continued. These behavioral results showed the development of the patterning behavior during the SA paradigm.

\section{Unit Response}

In marked contrast to the behavioral response, there was a significant effect of the SA schedule on the conditioned increase in hippocampal unit activity. The hippocampal units (CA1-3), as well as the dentate and septal units, exhibited a habituated response to the tone during pseudoconditioning, but the unit response was enhanced when the SA paradigm was introduced. The hippocampal unit activity did increase significantly for both $R$ and $N$ trials in the SA session immediately after the SA training was begun on Day 1 . The statistical analysis revealed significant differences between successive 120 -msec intervals (periods) in the hippocampal unit $[\mathrm{F}(3,208)=3.69$, $\mathrm{p}<$ $.05]$. However, there were no significant differences between treatments ( $R$ vs. $N$ trials) during the SA session on Day 1, thus the increment could be said to be a generalized, indiscriminate pattern for both $\mathrm{R}$ and $\mathrm{N}$ trials.

Since the same unit activity was continuously recorded on Day 1, through random presentation of the stimulus followed by the SA training, the significance of the response change from pseudoconditioning to the SA paradigm was tested statistically. This was performed by combining three different treatments of CS trials during pseudoconditioning, in $\mathbf{R}$ and $\mathrm{N}$ trials during the $\mathrm{SA}$ paradigm, for movement and units, respectively. The results indicated significant changes among treatments (random presentation, $\mathrm{R}$ and $\mathrm{N}$ trials) in the hippocampal $[F(2,312)=13.74, p<.01]$, dentate $[F(2,204)=$ $8.43, \mathrm{p}<.01]$, and septal $[\mathrm{F}(2,228)=6.53, \mathrm{p}<.01]$ groups. However, the same analysis applied to movements 


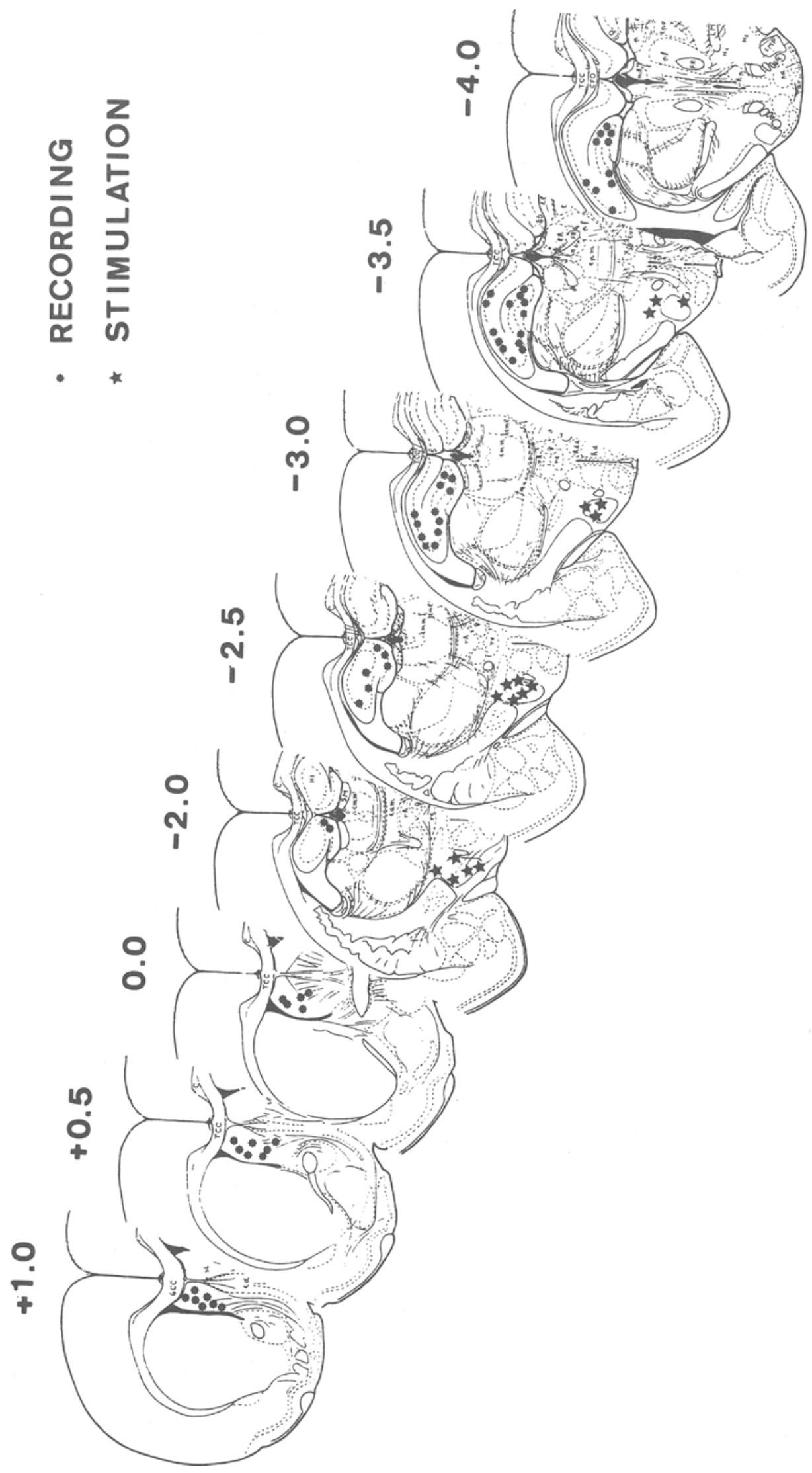

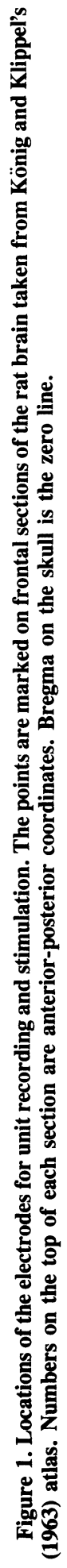




\section{PSED}

$\because$ C CS

\section{ALTERN DAY}

2

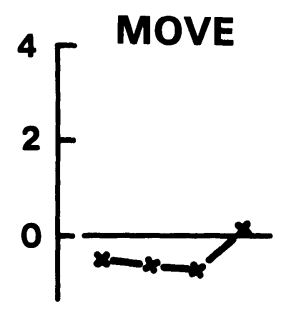

$n=17$
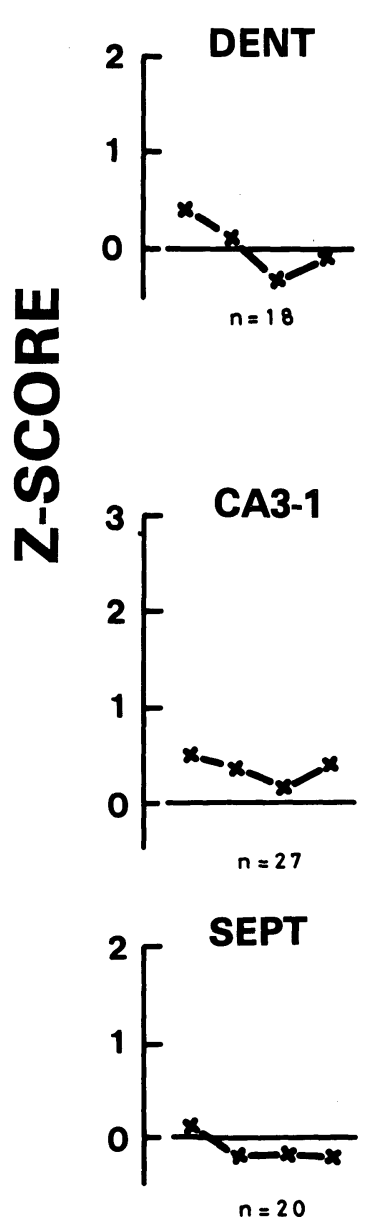

$F_{t}=2.04$
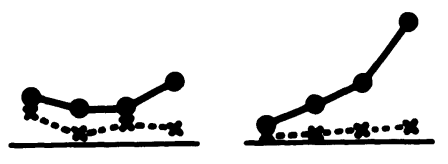

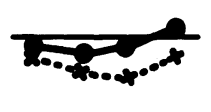

$n=17$

$F_{b}=0.83$
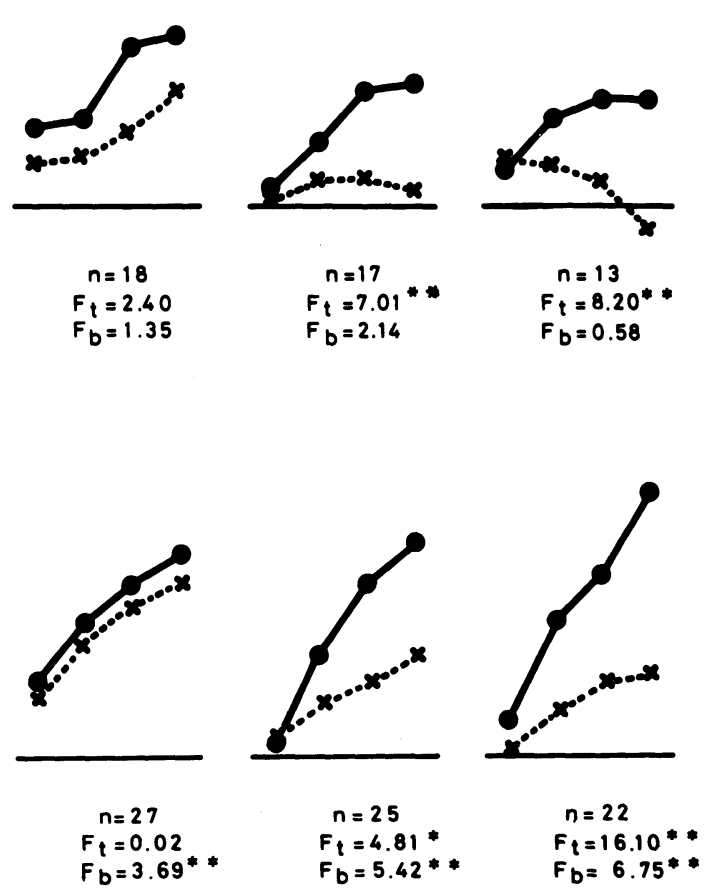

$n=17$

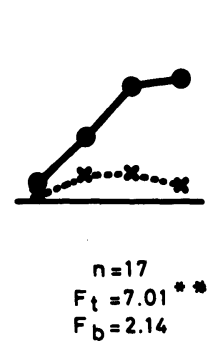

$F_{b}=2.14$

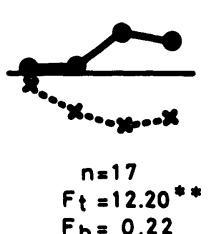

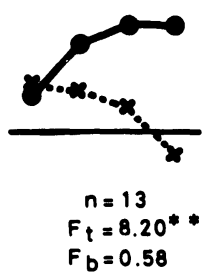

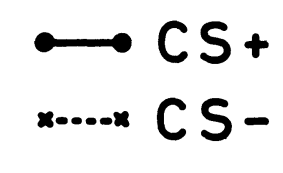

3

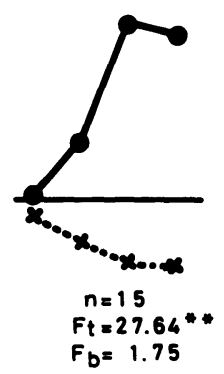

$F_{b}=0.58$

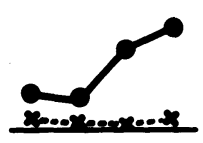

$$
\begin{aligned}
n & =20 \\
F_{t} & =3.39 \\
F_{b} & =0.26
\end{aligned}
$$

$$
\begin{aligned}
n & =18 \\
F_{t} & =3.07 \\
F_{b} & =0.85
\end{aligned}
$$$$
\begin{aligned}
n & =17 \\
F_{t} & =12.15 \\
F_{b} & =0.73
\end{aligned}
$$

Figure 2. Averaged response pattern for the various areas during four sessions of the experiment. Each pattern is composed of four successive 120 -msec periods of the CS-US interval. The values under each averaged curve are the results of a two-way analysis of variance (Edwards, 1968). An asterisk represents a significant difference at the .05 level; two asterisks represent a significant difference at the .01 level. The solid line during the SA paradigm represents $\mathrm{R}$ trials $(\mathrm{CS}+)$, and the dotted line represents $\mathbf{N}$ trials $(\mathrm{CS}-)$. Abbreviations: $\mathrm{Ft}=$ difference between treatments $(\mathrm{R}$ trials vs. $\mathrm{N}$ trials); $\mathrm{Fb}=$ difference between blocks (successive 120-msec periods). PSED = pseudoconditioning; ALTERN $=$ conditioning with the SA paradigm. 
yielded no significant differences among them $[F(2,192)$ $=2.04, \mathrm{p}>.1 \mathrm{l}$. Thus, the unit increment immediately after the change of the experimental paradigm from pseudoconditioning to the SA training on Day 1 preceded the behavioral change that appeared later on Day 2.

Next, to examine whether the units were significantly different on $\mathrm{R}$ and $\mathrm{N}$ trials after the SA paradigm was begun on Day 1 relative to the preceding CS trials during pseudoconditioning on the same day, the same analysis was applied to each group. Significant differences between $\mathrm{R}$ trials after the SA paradigm and the CS in pseudoconditioning were found in the dentate $[\mathrm{F}(1,136)$ $=19.28, \mathrm{p}<.01]$, hippocampal $[\mathrm{F}(1,208)=24.63, \mathrm{p}$ $<.01]$, and septal $[\mathrm{F}(1,152)=11.72, \mathrm{p}<.01]$ groups. Significant differences between $\mathrm{N}$ trials after the SA training and the CS in pseudoconditioning were also found in the dentate $[F(1,136)=6.74, p<.01]$ and hippocampal $[F(1,208)=19.58, p<.01]$ groups, but not in the septal group. These results clearly indicate that the change in dentate and hippocampal activity after the SA training was begun was due to generalized enhancement to the CS evidenced at the beginning of the shift to the SA paradigm after pseudoconditioning. These unit responses developed differential enhancement on $\mathrm{R}$ trials relative to $\mathrm{N}$ trials as the session progressed. Statistical analysis revealed significant differences between treatments for the dentate $[\mathrm{F}(1,128)=7.01, \mathrm{p}<.01]$ and hippocampal $[\mathrm{F}(1,192)$ $=4.81, \mathrm{p}<.01]$ groups on the 2nd day and for the septal $[F(1,128)=12.15, p<.01]$ group on the 3rd day of the training. The differential unit enhancement for $\mathbf{R}$ trials over the course of training thus appeared later and was generally correlated with behavioral differentiation.

Finally, to determine whether unit and movement activity on R trials in the pre-CS period during the SA training was different from that on $\mathrm{N}$ trials, averaged probability of spikes in the pre-CS period was estimated from the individual response topographies. A sample record taken from a hippocampal unit for this purpose is shown in Figure 3. As indicated in the figure, there was similar background activity in the pre-CS period of SA training for two different kinds of trials. Averaged probability of spikes in the pre-CS period for each group is presented in Table 1 . When the correlated $t$ test was applied to detect differences in each pair of $\mathrm{R}$ and $\mathrm{N}$ trials, the results

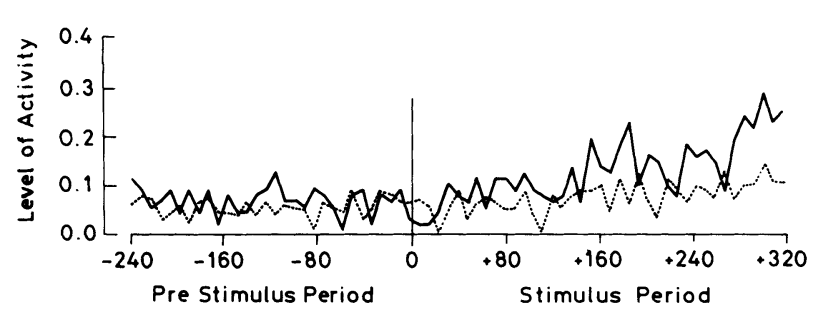

Milliseconds

Figure 3. A sample of hippocampal unit topography summed over 100 trials on Day 3 of single-alternation training. The solid line is for paired CS-US or reinforced (R) trials, and the broken line is for CS-alone or nonreinforced trials. Each point represents the relative probability of unit spikes during an 8-msec period. This record was reconstructed from a response histogram analyzed in 8-msec bins, including 30 bins of pre-CS period and 40 bins of CS period. The same auditory stimulus was presented for $R$ and $N$ trials at the period indicated by zero (CS onset) and continued to the end (1 sec).

failed to find any significant differences on the pre-CS firing levels between them (Table 1).

\section{DISCUSSION}

The results of the present experiment indicate an interesting differential relationship of hippocampal unit activity to the behavioral change found in trials immediately following a procedural shift. Although there was no change in behavior after training with the SA paradigm on Day 1, dentate and hippocampal activity significantly increased their firing rates to the conditioned stimulus. The enhancement of the unit response in these areas was, at an early stage, a generalized excitatory pattern. They increased indiscriminately for $\mathrm{N}$ and $\mathrm{R}$ trials. Dentate and hippocampal neurons apparently reflect a change of stimulus contingencies in the environment before behavioral learning to produce the conditioned movement. As shown in Figure 2, habituated response patterns are the general feature for both units and movement during the pseudoconditioning period. Although movement data on Day 1 remained almost the same after the SA training, the dentate and hippocampal neurons increased immediately after the shift from pseudoconditioning to the SA paradigm. The result was similar to that found in previous experiments using food reward (Disterhoft \& Segal, 1978;

Table 1

Average Level of Activity in the Pre-CS Period (Mean Spike Rate of 30 Bins $/ 8 \mathrm{Msec} / \mathrm{Bin}$ with Standard Deviation) Estimated for Reinforced (R) and Nonreinforced (N) Trials in Single-Alternation Training

\begin{tabular}{lcccccc}
\hline & $\mathrm{R}$ & $\mathrm{N}$ & $\mathrm{d}$ & $\mathrm{t}$ & $\mathrm{df}$ & $\mathrm{p}$ \\
\hline Movement & $0.085 \pm 0.068$ & $0.082 \pm 0.055$ & $0.003 \pm 0.062$ & 0.22 & 14 & n.s. \\
Dentate & $0.062 \pm 0.068$ & $0.054 \pm 0.062$ & $0.008 \pm 0.045$ & 0.64 & 12 & n.s. \\
Hippocampus & $0.058 \pm 0.054$ & $0.057 \pm 0.042$ & $0.001 \pm 0.019$ & 0.29 & 21 & n.s. \\
Septum & $0.074 \pm 0.066$ & $0.068 \pm 0.071$ & $0.007 \pm 0.021$ & 1.25 & 14 & n.s. \\
\hline
\end{tabular}

These background levels were evaluated from the data of 100 trials each on the second session of Day 3 (see Figure 3). A correlated t test was applied to every pair to evaluate the difference between $R$ and $N$ trials. The value of " $d$ " represents the mean difference between them, calculated for each correlated unit. 
Hirano, Best, \& Olds, 1971; Olds \& Hirano, 1969; Segal \& Olds, 1972, 1973) when the experimental procedures were changed from a random schedule to paired conditioning or from differential conditioning to reversal training. Considering those results together with the result of the present experiment, the main function of the dentate-hippocampus seems to be to monitor any change in the environmental stimulus contingencies: when a change in the stimulus contingency was introduced in the environmental context, particularly a change in the occurrence of the biologically meaningful stimulus, these structures were sensitive to the change. They showed increased unit response to the newly meaningful stimulus even when the behavioral movement remained constant. This is consistent with the idea that these structures detect an occurrence of mismatch by comparing the new context with those already acquired, as previously proposed by Gabriel, Foster, Orona, Saltwick, and Stanton (1980).

Since a tone stimulus was paired with rewarding brain stimulation in the present experiment, any place strategy was excluded for the animal. The animal could receive reinforcement on all $\mathrm{R}$ trials, regardless of his position in the apparatus. Therefore the mismatch was based mainly on the sequential change in the experimental paradigm, from random presentation to paired and nonpaired tone with rewarding brain stimulation. The results also seem to argue against the view that the hippocampus primarily contains a spatial map. There were no apparent spatial components in the experimental paradigm shift that was performed within the same apparatus on the same experimental day.

Lesion studies of the hippocampus in rats have consistently shown deleterious effects when a shift of behavior, such as alternation or reversal, was required (Johnson, Olton, Gage, \& Jenko, 1977; Kimble, 1975; Thompson \& Langer, 1963). The present data, showing the involvement of hippocampal units in an increased response to the newly significant stimulus, support the earlier findings. The results are also consistent with the previous findings of increased responsiveness of the hippocampal unit immediately after discrimination reversal (Disterhoft \& Segal, 1978). Thus, the rapid acquisition of enhanced responsiveness indicates the hippocampal function of monitoring the sequential change of the stimulus contingency. In this experiment, it was a change of conditional probability from random to the SA paradigm.

The comparison of behavioral acquisition and the unit change after the SA training presents an interesting feature (Figure 2). Following SA training, the animals acquired the differential movement response gradually over training by the 3 rd day of the experiment. The conditioned movement of the animals reflected an increased response to the paired stimulus ( $R$ trials) but not to the unpaired stimulus ( $\mathrm{N}$ trials). The movement on $\mathrm{N}$ trials exhibited the mild inhibitory response established in the preceding pseudoconditioning session. In contrast to this inhibitory pattern of the movement data, hippocampal and dentate units showed an increased response. This was true even on $\mathrm{N}$ trials, although to a lesser degree than on $\mathrm{R}$ trials.
Thus, the differential unit responses were acquired through generalized excitation of the nonpaired stimulus at full strength in early phases and its gradual decrease across training. The evidence for this differential development pattern between movement and hippocampal unit activity suggests a mediative role of stimulus significance processing for the hippocampus, which is not directly related to the hippocampal motor function suggested by Vanderwolf (1971).

This view is supported particularly by the fact that the dentate-hippocampal neuronal activity reached full differentiation between $\mathrm{R}$ and $\mathrm{N}$ trials by the 2 nd day of SA training, at which point only an early indication of behavioral differentiation had been acquired. Although the animal's movement increasingly acquired a greater degree of behavioral differentiation following overtraining on Day 3, dentate-hippocampal activity retained the response pattern acquired before the overtraining (see Figure 2). Thus, the results of the present experiment can be taken as support for the hypothesis of the hippocampal function related to a working memory, as proposed by Hoehler and Thompson (1979), in the sense that it mediated sequential processing for the temporal alternation of the paired and nonpaired trials. The result of higher levels of unit activity in the CS periods on $R$ trials than on $\mathrm{N}$ trials is consistent with their results with the rabbit nictitating membrane response.

The point on which the present experiment contradicts the working memory hypothesis, however, is the failure to find lower pre-CS background unit activity levels prior to the $\mathrm{R}$ trials than prior to $\mathrm{N}$ trials (Table 1), a phenomenon clearly shown in Hoehler and Thompson's (1979) results. Studies on patterning behavior, including temporal alternation, in rats have shown positive effects on appetitive conditioning (Capaldi, 1967; Capaldi, Veatch, \& Stefaniak, 1966; Gonzalez, Bainbridge, \& Bitterman, 1966; Heise, Keller, Khavari, \& Laughlin, 1969), which seems to produce even better SA learning than does rabbit nictitating membrane conditioning. These facts suggest that a superior effect would be expected when using the rat in appetitive conditioning; if so, it might be expected to produce greater aftereffects in the present experiment, in which rewarding brain stimulation provided reinforcement, than the former experiment, which used the nictitating membrane response in rabbits. However, one critical point should be mentioned. The conditioned nictitating membrane response is acquired by the development of a defense reaction, in which $\mathrm{R}$ trials may function as safety signals indicating that no shock will be delivered until an $\mathrm{N}$ trial occurs, whereas $\mathrm{N}$ trials may function as warning signals indicating that a safety period is over. In the present experiment, animals were reinforced with rewarding brain stimulation, so they were free from defense anticipation on any trial. The failure to obtain the pre-CS lower level of hippocampal activity in $\mathbf{R}$ trials relative to $\mathrm{N}$ trials in this experiment may be due to the absence of the warning signal that is present in the defense type of conditioning.

Finally, the fact that the hippocampal unit activity in- 
creased immediately after the shift on Day 1 before the behavioral change and the fact that there was a greater conditioned increase in the CS period for $R$ trials than for $\mathrm{N}$ trials during the SA paradigm should be considered together. As already discussed, the increase after the shift of the experimental procedures could reflect factors related to reference memory, based on a comparison between the meaning of a previously acquired stimulus and the changed meaning of the stimulus after the procedural modification. But the greater conditioned increase in the CS period for $\mathrm{R}$ trials than for $\mathrm{N}$ trials during the SA paradigm favors a participation of the working memory interpretation. However, the temporal SA paradigm includes in itself regularity of the stimulus event, since $\mathbf{R}$ and $\mathrm{N}$ trials consistently alternated during the course of the experiment. This procedure inevitably forms a context with regularity, which would be related to reference memory by definition because of the sequential stimulus sequence the animals were exposed to (they could receive reinforcement at every 120 -sec interval no matter what their behavior). Therefore, hippocampal unit increases to the CS on $\mathrm{R}$ trials relative to $\mathrm{N}$ trials might be considered to depend on the effect of reference memory of the sequential patterning. This sequential patterning could maintain increased unit response to $\mathrm{R}$ trials relative to $\mathrm{N}$ trials even if there were no positive aftereffect of the stimulus. Therefore, if this is the case, it is difficult to attribute the obtained results exclusively to the working memory hypothesis of hippocampal function. On the basis of the present results, the hippocampus appears to be involved in working memory with an interaction of reference memory. This conclusion appears to be in conflict with the conclusions of previous studies, but in future studies we need to separate further the effects of manipulations such as random intertrial intervals in the SA paradigm.

\section{REFERENCES}

Black, A. H., Nadel, L., \& O'Keefe, J. (1977). Hippocampal function in avoidance learning and punishment. Psychological Bulletin, 84, 1107-1129.

CAPALDI, E. J. (1967). A sequential hypothesis of instrumental learning. In K. W. Spence \& J. T. Spence (Eds.), The psychology of learning and motivation (Vol. 1, pp. 67-156). New York: Academic Press.

CaPaldi, E. J., Veatch, R. L., \& Stefaniak, D. E. (1966). Stimulus control of patterning behavior. Journal of Comparative and Physiological Psychology, 61, 161-164.

DisterhOFT, J. F., \& SEGAL, M. (1978). Neuron activity in rat hippocampus and motor cortex during discrimination reversal. Brain Research Bulletin, 3, 583-588.

EDWARDS, A. L. (1968). Experimental design in psychological research (3rd ed.). New York: Holt, Rinehart and Winston.

Gabriel, M., Foster, K., Orona, E., Saltwick, S. E., \& Stanton, M. (1980). Neuronal activity of cingulate cortex, anteroventral thalamus, in hippocampal formation and discriminative conditioning: Encoding and extraction of the significance of conditional stimuli. In A. N. Epstein \& J. M. Sprague (Eds.), Progress in psychobiology and physiological psychology (Vol. 9, pp. 125-231). New York: Academic Press.

Gonzalez, R. C., Bainbridge, P., \& Bitterman, M. E. (1966). Discretetrial lever pressing in the rat as a function of pattern of reinforcement, effortfulness of response, and amount of reward. Journal of Comparative and Physiological Psychology, 61, 110-122.
Heise, G. A., Keller, C., Khavari, K., \& Laughlin, N. (1969). Discretetrial alternation in the rat. Journal of Experimental Analysis of Behavior, $12,609-622$.

HiRano, T. (1984). Unit activity of the septo-hippocampal system in classical conditioning with rewarding brain stimulation. Brain Research, 295, 41-49.

Hirano, T., Best, P., \& Olds, J. (1971). Units during habituation, discrimination learning and extinction. Electroencephalography and Clinical Neurophysiology, 28, 127-135.

HoEHLER, F. K., \& LeONARD, D. W. (1973). Classical nictitating membrane conditioning in the rabbit (Oryctolagus cuniculus): Single alternation with differential intertrial intervals. Journal of Comparative and Physiological Psychology, 85, 277-288.

HoEHLER, F. K., \& THOMPSON, R. F. (1979). The effect of temporal single alternation on learned increases in hippocampal unit activity in classical conditioning of the rabbit nictitating membrane response. Physiological Psychology, 7, 345-351.

HoNIG, W. K. (1978). Studies of working memory in the pigeon. In S. H. Hulse, H. Fowler, \& W. K. Honig (Eds.), Cognitive processes in animal behavior (pp. 211-248). Hillsdale, NJ: Erlbaum.

Johnson, C. T., Olton, D. S., GAGE III, F. H., \& Jenko, P. G. (1977). Damage to hippocampus and hippocampal connections: Effects on DRL and spontaneous alternation. Journal of Comparative and Physiological Psychology, 91, 508-522.

Kimble, D. P. (1975). Choice behavior in rats with hippocampal lesions. In R. L. Isaacson \& K. H. Pribram (Eds.), The hippocampus (Vol. 2, pp. 309-326). New York: Plenum.

KöNIG, J. F. R., \& KLIPPEL, R. A. (1963). The rat brain: A stereotaxic atlas. Baltimore: Williams \& Wilkins.

NADEL, L. (1980). Cognitive and neural maps. In P. W. Jusczyk \& R. M. Klein (Eds.), The nature of thought: Essay in honor of D. O. Hebb (pp. 207-229). Hillsdale, NJ: Erlbaum.

NADEL, L., \& WillNer, J. (1980). Context and conditioning: A place for space. Physiological Psychology, 8, 218-228.

O'KeEfe, J., \& ConWAY, D. H. (1980). On the trail of the hippocampal engram. Physiological Psychology, 8, 229-238.

O'KeEFE, J., \& DostrovsKy, J. (1971). The hippocampus as a spatial map. Preliminary evidence from unit activity in the freely moving rat. Brain Research, 34, 171-175.

O'KeEfE, J., \& NADEL, L. (1978). The hippocampus as a cognitive map. Oxford: Oxford University Press.

OLDs, J. (1973). Multiple unit recordings from behaving rats. In R. F. Thompson \& M. M. Patterson (Eds.), Methods in physiological psychology: (Vol. 1, A). Bioelectric recording techniques, cellular processes and brain potential (pp. 165-198). New York: Academic Press.

Olds, J., Disterhoft, J. F., Segal, M., Kornblith, C. L., \& Hirsh, R. (1972). Learning centers of rat brain mapped by measuring latencies of conditioned unit responses. Journal of Neurophysiology, 35, 202-219.

Olds, J., \& HIRANO, T. (1969). Conditioned responses of hippocampal and other neurons. Electroencephalography and Clinical Neurophysiology, 26, 159-166.

Olton, D. S., Becker, J. T., \& HandelmanN, G. E. (1979). Hippocampus, space, and memory. Behavioral and Brain Sciences, 2, 313-365.

Olton, D. S., Becker, J. T., \& HANdelmanN, G. E. (1980). Hippocampal function: Working memory or cognitive mapping. Physiological Psychology, 8, 239-246.

Olton, D. S., Branch, M., \& Best, P. J. (1978). Spatial correlates of hippocampal unit activity. Experimental Neurology, 39, 295-308.

SAKURAI, Y., \& HIRANO, T. (1983). Multiple unit responses in reward areas during operant conditioning reinforced by lateral hypothalamic stimulation in the rat. Behavioral Brain Research, 8, 33-48.

Segal, M., \& OLDS, J. (1972). Behavior of units in hippocampal circuit of the rat during learning. Journal of Neurophysiology, 35, 680-690.

Segal, M., \& OLDS, J. (1973). Activity of units in the hippocampal circuit of the rat during differential classical conditioning. Journal of Comparative and Physiological Psychology, 82, 195-204.

THOMPSON, R., \& LANGER, S. K. (1963). Deficits in position reversal learning following lesions of the limbic system. Journal of Comparative and Physiological Psychology, 56, 987-995.

VANDERWOLF, C. H. (1971). Limbic-diencephalic mechanisms of voluntary movement. Psychological Review, 78, 83-113.

(Manuscript received June 25, 1984; revision accepted for publication April 12, 1985.) 